\title{
A single holiday was the turning point of the COVID-19 policy of Israel
}

\author{
Klausner, Ziv $\mathrm{PhD}^{1 \dagger}$; Fattal, Eyal $\mathrm{PhD}^{1^{*} \dagger}$; Hirsch, Eitan $\mathrm{PhD}^{2}$; \\ Shapira, Shmuel C., MD, $\mathrm{MPH}^{3}$ \\ ${ }^{1}$ Department of Applied Mathematics, Israel Institute for Biological \\ Research, Ness-Ziona, Israel \\ ${ }^{2}$ Environmental Sciences Division, Israel Institute for Biological \\ Research, Ness-Ziona, Israel \\ ${ }^{3}$ Director general, Israel Institute for Biological Research, Ness-Ziona, \\ Israel
}

\footnotetext{
* Correspondence to: Applied Math department, Israel Institute for Biological Research, P.O. Box 19, Ness-Ziona, 7410001, ISRAEL. Tel.: +972 8 9381794; fax: +972 8 9381432; e-mail: eyalf@ iibr.gov.il $\dagger$ These two authors contributed equally to the article
} 


\section{Abstract}

\section{Background:}

The impact of COVID-19 has been profound, and the public health challenge seem to be the most serious regarding respiratory viruses since the 1918 H1N1 influenza pandemic. In the absence of effective vaccine or biomedical treatment, the basic rules of public health measures have not changed, namely public distancing.

\section{Methods:}

We analyzed epidemiological investigation reports during the first month of the outbreak in Israel. In addition, we present a deterministic compartment model and simulations of several scenarios emphasizing quarantine and isolation policies given their efficiency.

\section{Results:}

We identify an abrupt change from controlled epidemic regime to an exponential growth $\left(R_{0}=2.19\right)$ in light of the actual policy-makers decisions and public behavior in Israel. Our analysis show that before the abrupt change, the new cases trend was due to returning citizens infected abroad. The abrupt change followed a holiday in which social distancing was clearly inefficient and many public gatherings were held. We further discuss three different modeled scenarios of quarantine efficiency: high-, medium-, and low-efficiency.

\section{Conclusions:}

Israel early lessons show that there is no allowance to compromise with the directive of social distancing. Even before the onset of the pandemic in Israel, finetuned but determined early decisions were taken by policy makers to monitor flight arrivals from Covid-19 affected regions and to limit public gatherings. Our analysis show that one particular holiday has shifted the occurrence curve from controlled 
67 regime to exponential growth. Therefore, even a short lapse in public responsiveness

68 can have a dramatic effect.

\section{1. Introduction}

Since its emergence the impact of COVID-19 has been profound, and the

74 public health challenge seem to be the most serious seen in a respiratory virus since

75 the 1918 H1N1 influenza pandemic (Soper 1919). In this study we present the results

of epidemiological data and modelling of one month since the onset of the outbreak in

Isreal, addressing public events occurring during this period and the sensitivity to a

number of public health measures focusing on social distancing (quarantine and

isolation).

The epidemiological data studied, consisting of 381 laboratory confirmed

COVID-19 cases, has been obtained from the epidemiological investigation reports

that were released by the Israeli Ministry of Health (Israeli Ministry of Health, 2020).

83 This allowed us to identify and separate the incoming from abroad (which policy

84 required to enter quarantine on arrival) to the local cases, thus analyzing the net

85 contribution of local infections.

In addition, we present an extended deterministic SEIR (Susceptible, Exposed,

87 Infectious, and Recovered) model to simulate disease outbreak scenarios. In

88 particular, the model includes quarantine of asymptomatic suspected population

89 (exposed) and isolation of symptomatic and infectious patients. The model takes into

90 account the efficiency of the quarantine and isolation measures. We discuss three

91 different quarantine efficiency scenarios: high-efficiency, medium-efficiency, and 
low-efficiency. The resulting analysis from the epidemiological cases data are discussed in light of public events and compared to model simulations. We analyze and discuss an abrupt change from controlled epidemic regime to an exponential growth regime in light of policy makers' decisions and public behavior.

\section{Methods}

The dynamics of spread of epidemics as well as the quarantine-isolation policy of Israel was modeled using the SEQIJR model (e.g. Gumel, et al., 2004). This is a deterministic compartmental model which allows the implicit inclusion of biological epidemiological phases (including incubation period) as well as governmental interventions such as quarantine and their actual efficiency of implementation. A successful a posteriori implementation of this model to the transmission dynamics and control of the SARS epidemics in Toronto, Hong Kong, Singapore and Beijing is given in Gumel, et al., 2004. The model consists of a system of 7 dynamical equations and 15 parameters. For details of the model and its parameters see the online supplementary information.

The data analyzed in this study was obtained from the epidemiological investigation reports that were released by the Israeli Ministry of Health (Israeli Ministry of Health, 2020). From the total of 883 PCR laboratory confirmed COVID19 cases we analyzed the 384 cases that were investigated epidemiologically, allowing us to separate the incoming from abroad (quarantined on arrival by policy) to local cases. This allowed us to separate the imported cases (travelers arriving from abroad) from the locally infected cases. The data spans over the first month of the COVID-19 outbreak in Israel, beginning in February $21^{\text {st }} 2020$ and going until March $20^{\text {th }}$. We further note that during the examined period the number of PCR tests 
medRxiv preprint doi: https://doi.org/10.1101/2020.03.26.20044412; this version posted May 4, 2020. The copyright holder for this preprint

(which was not certified by peer review) is the author/funder, who has granted medRxiv a license to display the preprint in perpetuity.

All rights reserved. No reuse allowed without permission.

$-5-$

117 performed rose daily, reaching 1869 at the end of the period. However, the proportion

118 of positive tests remained approximately the same, as $7.9 \%$ (Israeli Ministry of

119 Health, 2020).

120 The incidence curve was modelled as a fit to an exponential growth function

121 (de Silva, et al., 2009; Zhao, et al., 2020). Several serial interval distributions that

122 were estimated for COVID-19 were examined (Nishiura, et al., 2020; Ganyani, et al.,

123 2020; Zhao, et al., 2020).

124

125 3. Results

126 The dynamics of epidemic spread in Israel in terms of daily reported

127 confirmed cases is shown in fig. 1. There are two distinct regimes in the curve. The

128 first ended in March 12, 2020 in which the local to travel associated infection ratio

129 was around 1:3 (up to 1:2.5), i.e., for every three imported cases, there was one local

130 infection. The second period, began a day later. The first distinct sign for the change

131 was evident on March $14^{\text {th }}$ were the ratio rose to $1: 2$, then continued to rise on March

$13217^{\text {th }}$ to $1: 1.5$ and finally, after a month into the epidemic in Israel, on March $21^{\text {st }}$ there

133 were more local infections in Israel than imported cases (the ratio was above 1:1).

134 March $12^{\text {th }}$ is two days after the Jewish holiday of Purim, which this year was

135 celebrated on March $10^{\text {th }}$. Purim customs include wearing masks and costumes and

136 holding public celebrations, parades as well as religious gatherings. Because Purim is

137 also a school holiday, many celebration are held a day or two earlier.

138 


\section{$-6-$}

139

140

141

142

143

144

145

146

147

148

149

150

151

152

153

154

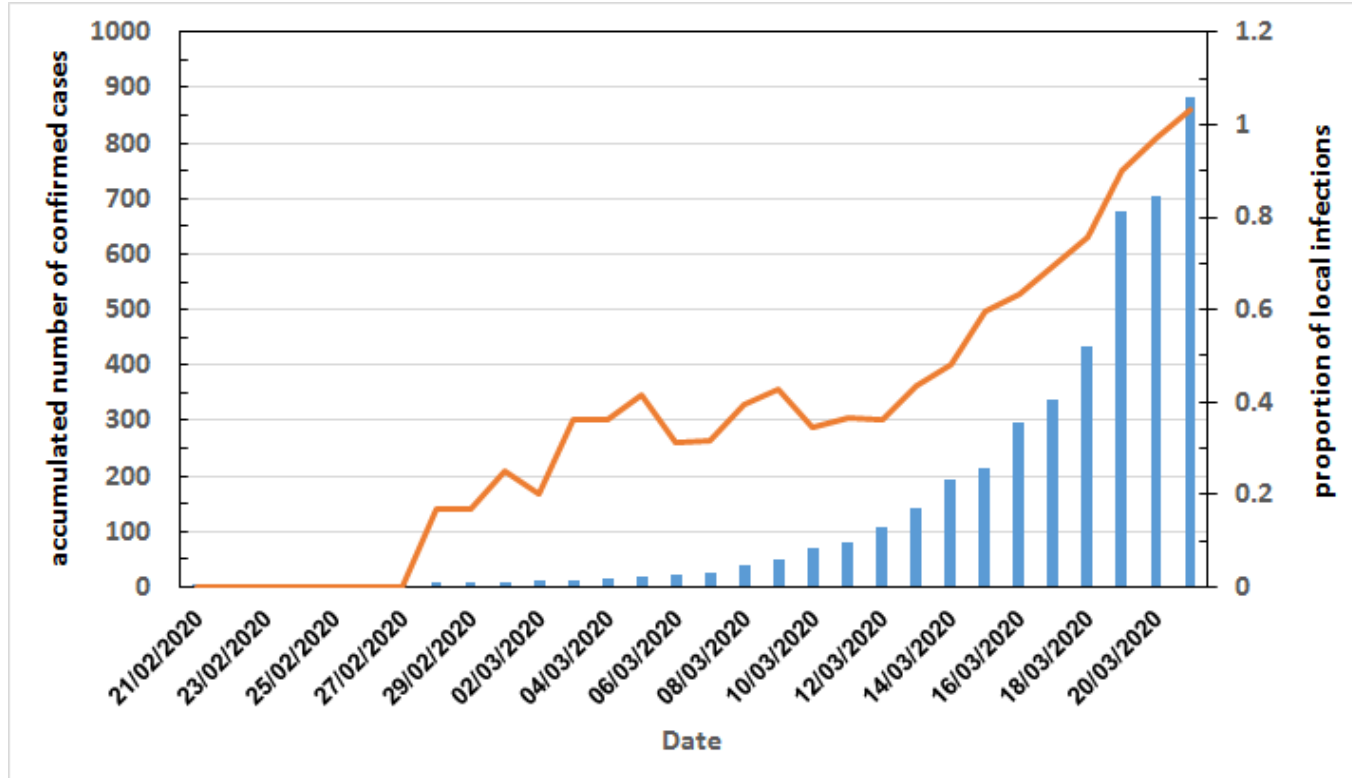

FIG. 1. Accumulated reported confirmed COVID-19 cases in Israel (blue bars)

and the ratio of local infections to travel associated infections (orange line)

The effective reproduction number, $R_{0}$, was estimated for the daily new cases data of the first month of the COVID-19 epidemic. The lowest estimated $R_{0}$ was 2.08 (95\%CI 1.93-2.6) for the Gamma distributed serial interval with mean 4.4 and SD 3 days (Zhao, et al., 2020). The highest estimate was 2.37 (95\%CI 2.16-2.61) for the Gamma distributed serial interval with mean 5.2 and SD 2.8 days (Ganyani, et al., 2020). The mean $R_{0}$ overall the serial interval distributions examined, was 2.19 . The SEQIJR model solutions are characterized by 3 locally stable equilibrium points in parameters space. These refer to the following regimes or types of dynamics of epidemic spread: controlled (decaying), flattened, uncontrolled (baseline SEIR model; further details can be found in the supplementary material). In this study we simulated three scenarios, the first corresponding to the first equilibrium and two corresponding to the second: 
medRxiv preprint doi: https://doi.org/10.1101/2020.03.26.20044412; this version posted May 4, 2020. The copyright holder for this preprint

(which was not certified by peer review) is the author/funder, who has granted medRxiv a license to display the preprint in perpetuity.

All rights reserved. No reuse allowed without permission.

$-7-$

155

156

157

158

159

160

161

162

163

164

165

166

167

168

169

1. A controlled high-efficiency quarantining (decaying green curve in Fig. 2). This regime is characterized by an early entry of asymptomatic suspected population to home quarantine. Moreover we assume the infectiousness in home quarantine is one sixth compared to free asymptomatic. The efficiency of isolation is $70 \%$.

2. A flattened for medium-efficiency quarantining (purple curve in Fig.

2). This regime is characterized by a late entry of asymptomatic suspected population to home quarantine. Moreover we assume the infectiousness in home quarantine is one third compared to free asymptomatic. The efficiency of isolation is $70 \%$.

3. A flattened for low-efficiency quarantining (light-blue curve in Fig. 2). This regime is characterized by a late entry of asymptomatic suspected population to home quarantine. Moreover we assume the infectiousness in home quarantine is similar to free asymptomatic. The efficiency of isolation is $30 \%$.

170 As discussed above, the dynamics of epidemic spread in Israel until March 8, 2020

171 corresponds to the controlled regime characterizes with $R_{0}$ of the order of half (green

172 curve in Fig. 2). On the other hand, after March 8, 2020 the regime corresponds to the

173 flattened regime with low-efficiency quarantining and $R_{0}=2.19$. 


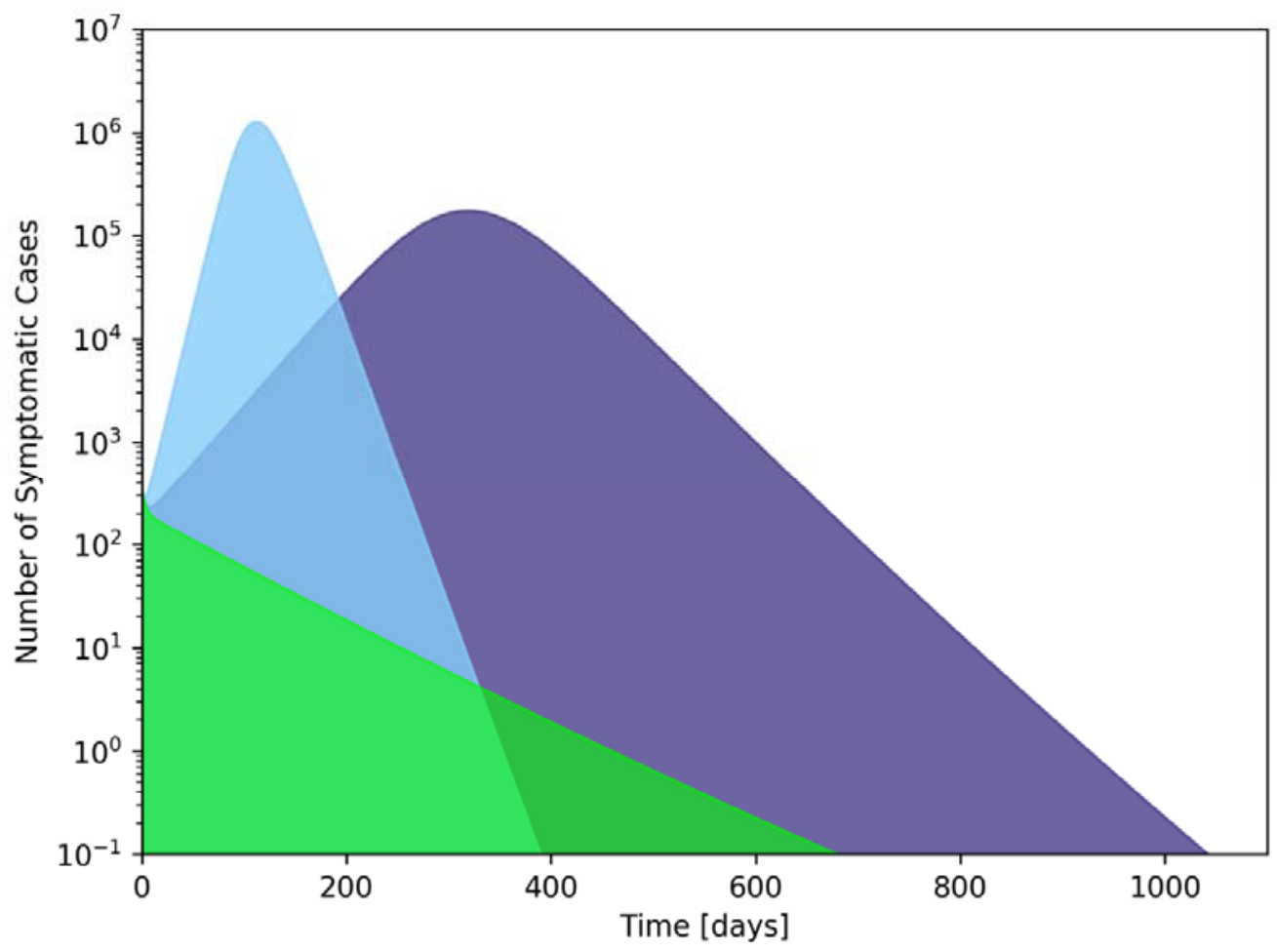

174

176 simulations for 3 scenarios: green - high-efficiency quarantining, purple - medium-

177 efficiency quarantining, light blue - low-efficiency quarantining.

\section{Discussion}

Israel has begun early its mitigation policy against the COVID-19 epidemic.

181 From the beginning of February, it was decided: to close all border passages (via land,

182 sea and air) to people that are not Israeli citizens or resident that have visited China

183 recently; to stop all direct flights from Israel to China and to require Israeli citizens

184 returning from China or that were in touch with a confirmed COVID-19 patients to a

18514 days home quarantine. A short while later, the quarantine requirement was

186 expanded to other Asian countries. The first COVID-19 patients in Israel were two

187 passengers that returned from the "Diamond Princess", in 21 and 23 of February. 
188 They entered directly to hospital isolation. A week later, a passenger from Italy was

189 diagnosed as a COVID-19 patient, and Italy was added to the list of countries that

190 require 14 days quarantine.

191 The quarantine-isolation policy succeeded in keeping the rate of daily new

192 cases small, up until March $9^{\text {th }}$. Then, 4 days later, a sudden change of regime has

193 occurred, which was manifested by the distinct change of the epidemic curve of Israel

194 towards exponential growth. March $15^{\text {th }}$ marks the first time that the daily new cases

195 of locally infected were higher than the new travel associated cases.

196 The timing of this abrupt change is not of coincidence. Regarding the cases

197 arriving from abroad, a requirement for home quarantine affecting all travelers

198 arriving began on Match $9^{\text {th }}$. Moreover, during the period between March $9^{\text {th }}$ to $11^{\text {th }} \mathrm{a}$

199 Jewish holiday, Purim, was celebrated. This holiday is characterized by big parades

200 organized by local municipalities, as well as religious gatherings and privately

201 organized parties. Although authorities cancelled the public parades, many privately

202 organized and religious crowding had occurred. Regrettably, these drove Israel from a

203 controlled, mitigated regime to an exponential growth, as described in the results

204 section. Therefore, despite its intense efforts, Israel's effective $R_{0}$ for the period

205 ending in March $20^{\text {th }}$ stands on around 2.19, slightly smaller than the $R_{0}$ of 2.6-3.2

206 estimated for the republic of Korea and Italy, for the period ending in March $5^{\text {th }}$.

207 Such abrupt transition based on social behavior emphasizes the fragility of mitigation 208 policies.

209 We therefore emphasis the importance of early fine-tuned but intense

210 directives for social distancing and isolation measures. This study clearly

211 demonstrates the lesson learned from the Israeli policy, that even a short lapse in 
medRxiv preprint doi: https://doi.org/10.1101/2020.03.26.20044412; this version posted May 4, 2020. The copyright holder for this preprint (which was not certified by peer review) is the author/funder, who has granted medRxiv a license to display the preprint in perpetuity.

All rights reserved. No reuse allowed without permission.

$-10-$

212 public responsiveness can have a dramatic effect on public health during pandemic

213 outbreak.

214

215

216

217 References

218 1. Israel Ministry of Health. Information on confirmed patients and COVID-19

219 press releases. https://govextra.gov.il/ministry-of-health/corona/corona-

220 virus/spokesman-messages-corona/. Accessed Mar 22, 2020.

221 2. De Silva UC, Warachit J, Waicharoen S, Chittaganpitch M. 2009. A

222 preliminary analysis of the epimemiology of Influenza A(H1N1)v virus

223 infection in Thailand from early outbreak data. Eurosurveillance: 14(31).

224 3. Nishiura H, Linton NM, Akhmetzhanov AR. 2020. Serial interval of novel

225 coronavirus (COVID-19) infections. International Journal of Infectious

226 Diseases DOI: 10.1016/j.ijid.2020.02.060

227 4. Zhao S, Gao D, Zhuang Z, Chong MKC, Cai Y, Ran J, Cao P, Wang K, Lou

228 Y, Wang W, Yang L, He D. 2020. Estimating the serial interval of the novel

229 coronavirus disease (COVID-19): A statistical analysis using the public data in

230 Hong Kong from January 16 to February 15, 2020. preprint is under

231 consideration at Infectious Diseases of Poverty. DOI: 10.21203/rs.3.rs-

$232 \quad 18805 / \mathrm{v} 1$

233 5. Ganyani T, Kremer C, Dongxuan C, Torneri A, Faes C, Wallinga J, Hens N.

234 Estimating the generation interval for COVID-19 based on symptom onset

235 data. medRxiv doi:10.1101/2020.03.05.20031815 
medRxiv preprint doi: https://doi.org/10.1101/2020.03.26.20044412; this version posted May 4, 2020. The copyright holder for this preprint (which was not certified by peer review) is the author/funder, who has granted medRxiv a license to display the preprint in perpetuity. All rights reserved. No reuse allowed without permission.

$-11-$

236 6. Gumel AB, Ruan S, Day T, Watmough J, Brauer F, van den Driessche P,

237 Gabrielson D, Bowman C, Alexander ME, Ardal S, Wu J, Sahai BM.

238 Modelling strategies for controlling SARS outbreaks. Proc Biol Sci. 2004;

239 271(1554):2223-32. doi:10.1098/rspb.2004.2800

240 7. Soper GA. 1919. The lessons of the Pandemic. Science 49(1274): 501-506.

$241 \quad$ DOI: $10.1126 /$ science.49.1274.501

242 8. Zhuang Z, Zhao S, Lin Q, Cao P, Lou Y, Yang L, Yang S, He D, Xiao L.

243 2020. Preliminary estimating the reproduction number of the coronavirus

244 disease (COVID-19) outbreak in Republic of Korea and Italy by 5 March

245 2020. medRxiv preprint DOI: https://doi.org/10.1101/2020.03.02.20030312 